O cinema como ferramenta para a discussão bioética em um grupo hospitalar no sul do Brasil

\section{Rech, Caroline}

Grupo Hospitalar Conceição, Porto Alegre, Brasil. E-mail: carolrechmd@gmail.com

\section{Amoretti, Rogério}

Grupo Hospitalar Conceição, Porto Alegre, Brasil

PALAVRAS-CHAVE: bioética; cinema; educação; dignidade

Introdução - As manifestações culturais e artísticas podem ser consideradas um reflexo dos pensamentos e ações dos seres humanos. Na Grécia Antiga, o teatro já era utilizado como ferramenta para a análise de arquétipos do comportamento humano, permitindo, através da identificação dos expectadores com as situações retratadas pelos atores, a reflexão acerca de situações vivenciadas no dia-a-dia. Atualmente, o cinema assumiu o posto de manifestação artística com maior difusão e visibilidade nas sociedades contemporâneas. Várias são as produções cinematográficas que abordam temáticas conflitivas, que podem ser analisadas sob a ótica da Bioética. Método - Com o objetivo de aproximar a Bioética da vida cotidiana das pessoas, o Comitê de Bioética do Grupo Hospitalar Conceição (GHC) instituiu o projeto "Bioética e Cinema" em março de 2015, com encontros a cada 2 meses abertos a toda a comunidade hospitalar, com a realização de registros escritos das discussões. Resultados Até o momento foram realizados 10 encontros; a média de participantes tem sido de 20 pessoas, das mais diferentes áreas do GHC - higienizadores, assistentes sociais, técnicos de enfermagem, enfermeiros, médicos, psicólogos, fisioterapeutas, farmacêuticos, técnicos administrativos, residentes e estudantes. As produções discutidas até o momento foram: "Wit - uma lição de vida", "Intocáveis", "Para sempre Alice", "Eu, Daniel Blake", "Up - altas aventuras", "Feliz Natal", "Gattaca", "The true cost o verdadeiro custo da moda", "Uma prova de amor" e "Um golpe do destino". Os principais temas abordados evidenciados na análise dos registros foram: terminalidade, sacralidade da vida, relações entre profissionais e pacientes, comunicação de notícias difíceis, consentimento informado, preconceito e racismo, vulnerabilidade, humanização das práticas de cuidado, desigualdades sociais, justiça social, ciclo da vida, envelhecimento e vida com doenças degenerativas, relações entre gerações, bioética ambiental e conservação do meio-ambiente, multiculturalismo, manipulação genética, relações entre mercado e saúde, autonomia do adolescente, adoecimento em profissionais da saúde. A importância da dignidade como valor central para os direitos humanos e para o cuidado em saúde foi tema recorrente em todas as discussões. Conclusões - Ao longo dos encontros, o Comitê de Bioética pôde comprovar a validade do cinema como ferramenta agregadora dos trabalhadores e que proporciona a apresentação da Bioética para os mais diferentes grupos de profissionais, ampliando, assim, a inserção da reflexão ética na vida cotidiana destas pessoas.

AGRADECIMENTOS: os autores agradecem à Redbioética Unesco, cujo curso Bioética Clínica e Social inspirou a realização deste projeto institucional.

\section{REFERÊNCIAS:}

[1] S. ALEKSANDROVA-YANKULOVSKA, Nurs Ethics, 23(2), 167 (2016).

[2] C.M. RATES, L.M. SILVA, L.M. PEREIRA, J.D.R. PESSALACIA, Invest Educ Enferm, 32(3), 421 (2014).

[3] J.C. SÁNCHES, J.C. GUTIÉRREZ, M.D. MORALES, Fam Med, 42(6), 398 (2010).

[4] P.H.N. CEZAR, A.P. GOMES, R. SIQUEIRABATISTA, Rev Bras Educ Med, 35 (1) , 93 (2011). 